\title{
Study on Some Improvised Revolvers
}

\author{
Ajitesh Pal* and H. K. Pratihari \\ Tripura State Forensic Science Laboratory, India
}

Submission: March 08, 2017; Published: April 19, 2017

*Corresponding author: Ajitesh Pal, Tripura State Forensic Science Laboratory, Agartala, Pin-799015, India, Email: ajiteshp@rediffmail.com

\begin{abstract}
There are different types of small firearms including the revolver which is a rifled handgun having a revolving cylinder with chamber for loading cartridges. Revolvers of different calibers are available varying from $3 \mathrm{~mm}$ to about $15 \mathrm{~mm}$. These small firearms are usually used by police personnel/civilians for self-defense or the defense of others; and military personnel during combat. Considering the revolver's various advantages, such firearms are clandestinely manufactured by skilled gunsmith in various locations in India and smuggled out of the country by weapons traffickers for sale and global distribution. As such, gun control has become difficult. Out of total gun-violence cases received in the laboratory for last ten years, it is seen, $2 \%$ of the total (1635 number) cases are contributed by improvised revolvers. Such indigenous firearms are meticulously designed to fire different factory made ammunition. In this paper, some improvised revolvers showing their action mechanism, physical features, indigenous body parts used for making them have been discussed in detail. The database on improvised revolvers will be useful to law enforcement agencies, forensic ballistics experts, judicial officers and legal experts in their professions since no systematic research has been done or sufficient literature is available on the subject.
\end{abstract}

Keywords: Improvised Revolver; Action Mechanism; Caliber; Gun-Violence; Physical Features

\section{Introduction}

India has a very strong firearm Act (Arms Act 1959). The possession and ownership of different firearms are closely regulated by the government/law enforcement agency. However, the use of country-made gun for criminal activities is very alarming within India. It is reported that a few years back about $88 \%$ of the gun-violence were committed by illegal or unlicensed firearms [1]. The use of improvised guns for criminal activities is rising in an exponential manner. The law enforcement agencies are not able to control unlicensed firearms since these are available in illicit market which is unregulated. Moreover, due to insufficient intelligence and manufacturing in remote areas, the police are not able to control firearm trafficking [2,3]. As per National Crime Records Bureau (NCRB), Govt. of India report [1] of the year 2011, the number of victims murdered by unlicensed firearm is seven times more than those killed by the licensed firearms. There are about 3,00,000 illegal firearms [4,5] in the national capital and following reasons for the increase of such firearms are [6]:

A. Possession of gun considered as status symbol for some individual in the society

B. Easy procurement without license or registration to escape tracing

C. An alternative against costly one
D. Easy availability of different indigenous body parts in the local market

E. Inadequate law to punish the manufacturer/trafficker/ user

F. Convenient to conceal and escape detection

G. Huge demand in clandestine market by criminal element

H. Easy availability of improvised revolvers of various caliber at low cost

\section{Material and Methods}

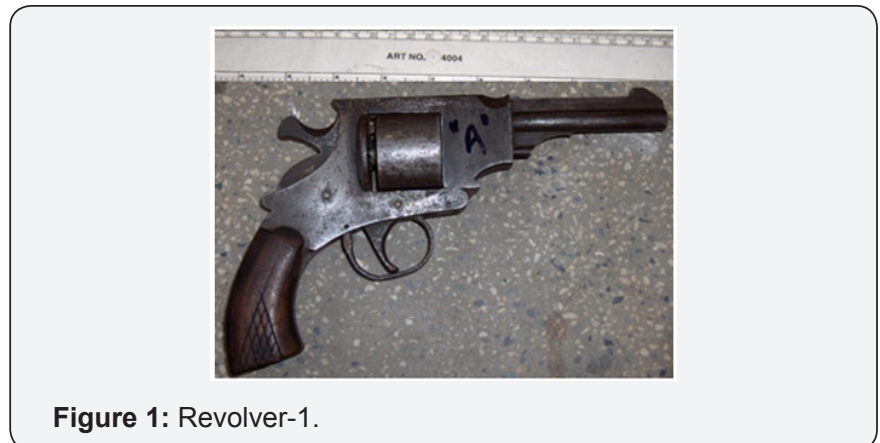

The improvised revolvers of .38 caliber received in four different cases are studied in this paper. Before test firing was 
completed, revolvers were examined thoroughly with Borescope (KARL STORZ, Germany). The revolvers' overall length, barrel length, muzzle diameter, breech diameter, trigger pull and weights were also measured with the scientific instrument available in the laboratory (Figures 1-5).
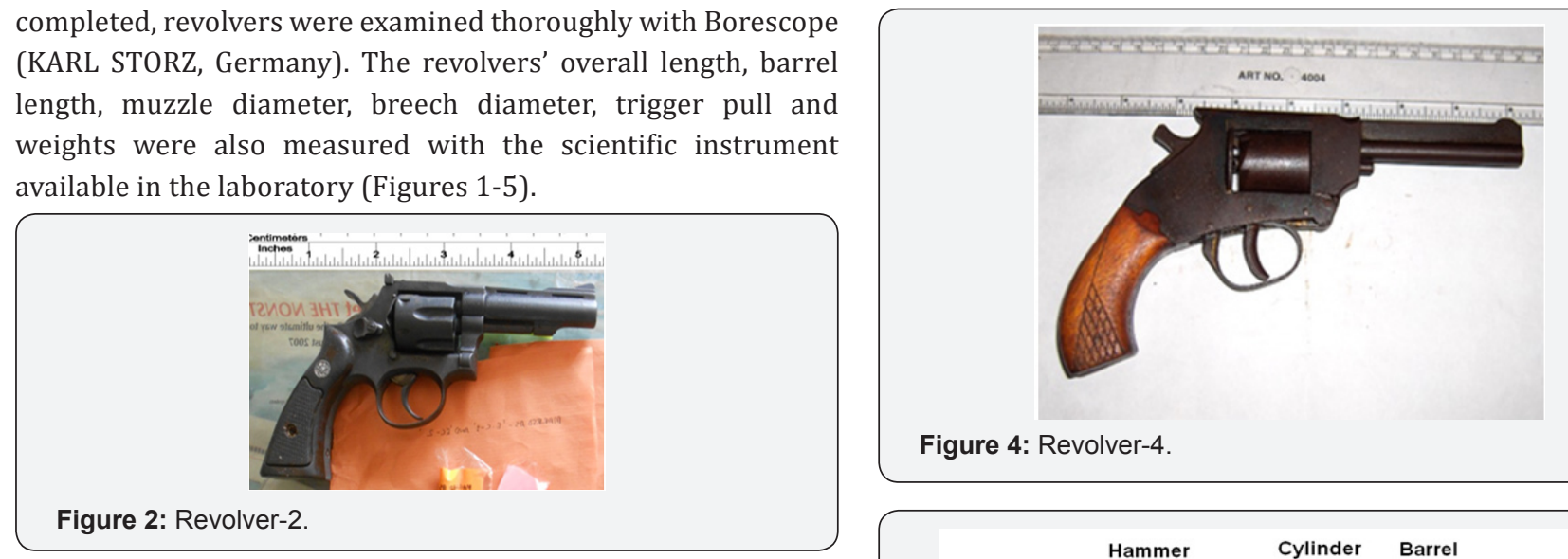

Figure 4: Revolver-4.

Figure 2: Revolver-2.
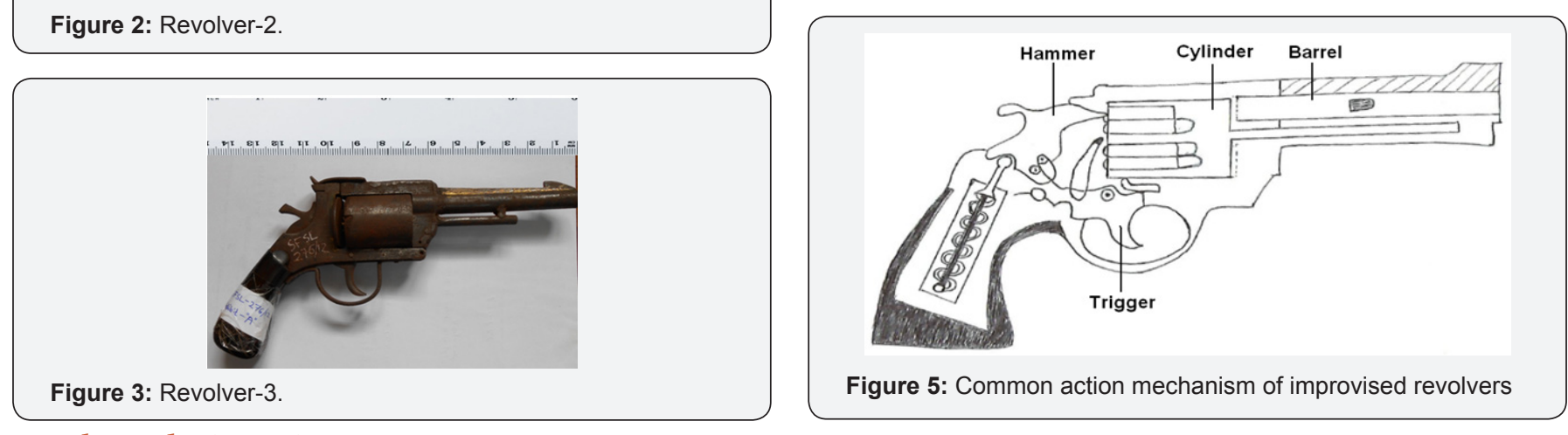

Results and Discussion

Table 1: Specifications of Revolvers.

\begin{tabular}{|c|c|c|c|c|}
\hline Specification & Revolver-1 & Revolver-2 & Revolver-3 & Revolver-4 \\
\hline Overall length (cm) & 23 & 23.5 & 22.9 & 23.4 \\
\hline Barrel length (cm) & 8.6 & 8.5 & 8.7 & 9.1 \\
\hline Muzzle diameter (mm) & 8.72 & 8.71 & 8.7 & 9.75 \\
\hline Breech diameter (mm) & 8.9 & 8.8 & .3 & .38 \\
\hline Caliber & .38 & .38 & 6 & 6 \\
\hline Capacity of Cylinder & 6 & 6 & 712 & 614 \\
\hline Weight of revolver (g) & 711 & 723 & 7 & 8 \\
\hline Trigger Pull (Kg-wt) & 6.2 & 5.4 & Absent & Absent \\
\hline Rifling & Absent & Absent & single action & single action \\
\hline Action & single action & single action & Safety switch absent & Safety switch absent \\
\hline Peculiarity & Safety switch absent & Safety switch absent & & \\
\hline
\end{tabular}

All the improvised revolvers discussed in the paper are devoid of logo, code number including manufacturer's identity having unfinished look. The physical features of the improvised revolvers are shown in (Table 1). Their muzzle and breech diameter vary from firearm to firearm. The revolvers of a specific caliber are made skillfully to fire factory made ammunition of same caliber. The measurement of muzzle velocity, range of firing etc found not at par with the standard revolvers due to the substandard barrel length, internal diameter and absence of rifling. Further, the body parts of revolvers are made of indigenous material and sometimes insufficient to withstand pressure resulting explosion of barrel. The information furnished on CM revolvers on various points will be of much helpful to the firearm expert and users.

\section{Conclusion}

The present study deals with the examination of improvised revolvers received in the laboratory for forensic study. It is observed that crude materials locally available are used for making such firearms by gunsmith. Various parameters of the revolvers have been recorded to prepare a database for further study. Test firing by these revolvers have been conducted successfully in the laboratory and the muzzle velocity, range of firing etc found to be less than the standard.

In order to control the illegal gun culture among the criminal elements, following action plans are recommended by way of suggestion: 
A. Possible sources of manufacturing illicit firearms and trafficking route are to be identified through proper intelligence feedback

B. Stringent exemplary punishment to the king-pin of such illicit trade and Person in possession/use

C. Regular check/frisking at suspicious places by police

D. Stricter gun control law

E. Investigation using forensic evidence is to be strengthened.

F. Much research has to be undertaken to study the tool marks present on the body of such illegal firearms to identify the offenders.

\section{Acknowledgement}

Authors are thankful to Dr. M.S. Rao, Ex-Chief Forensic Scientist, DFS, New Delhi, MHA, Govt of India for his valuable suggestions and one of our staff Mr. Rajib Majumder for his assistance.

\section{References}

1. National Crime Records Bureau (2011) Government of India. Crime in India: 2011 Statistics. Ministry of Home Affairs.

2. Pragya Arya (2016) Delhi Is Fast Becoming A Safe Heaven For The Huge Illegal Gun Trafficking Industry by Indiatimes.

3. Mark Magnier (2012) Gun culture spreads in India. Los Angeles Times.

4. Dikshit P (2009) Weaponisation of Indian Society through Illicit Arms Proliferation, Production and Trade. In: Binalakshmi Nepram, (Ed.), India and the Arms Trade Treaty. India Research Press, New Delhi, India, p. 43-45: 35-36.

5. Thejaswi HT, Kumar A, Jegadheeshwara raj (2013) Desi-Katta (Country-Made Firearm) and Wound Ballistics A Review. J Indian Acad Forensic Med 35(2): 165-169.

6. Pal A, Pratihari HK (2014) Examination of Some Indian Homemade/ Improvised Firearms and Their Ammunition. AFTE Journal 46(3): 234-237.

\section{Your next submission with Juniper Publishers will reach you the below assets}

- Quality Editorial service

- Swift Peer Review

- Reprints availability

- E-prints Service

- Manuscript Podcast for convenient understanding

- Global attainment for your research

- Manuscript accessibility in different formats

( Pdf, E-pub, Full Text, Audio)

- Unceasing customer service

Track the below URL for one-step submission https://juniperpublishers.com/online-submission.php 